\title{
1st International congress on mycorrhizal symbiosis: ecosystems and environment of Mediterranean area (MYCOMED)
}

\author{
Diégane Diouf • Marc Ducousso • Silvio Gianinazzi • \\ Michel Lebrun · Corinne Leyval
}

Received: 16 March 2011 / Accepted: 7 April 2011 /Published online: 4 May 2011

(C) Springer-Verlag 2011

The congress MYCOMED was held from 11 to 13 October 2010 in Marrakesh, Morocco, and organised by Prof. M. Hafidi (University Cadi Ayyad of Marrakesh) and Dr. R. Duponnois (IRD, LSTM, Montpellier). It brought together 180 participants from 22 countries with the aim to present recent results and concepts concerning the expected benefits of mycorrhizal symbiosis for the conservation of Mediterranean endemic plant diversity and for the rehabilitation of degraded soils (e.g. mining sites). Below, we present a synthesis of the scientific content and perspectives for further development in the research area. Oral presenta-

\section{Diouf}

Laboratoire Commun de Microbiologie IRD/ISRA/UCAD, Departement de Biologie Vegetale, Centre de Recherche de Bel-Air, University Cheikh Anta Diop, BP 1386, CP 18524 Dakar, Senegal

e-mail: diegane.diouf@ird.sn

M. Ducousso $(\bowtie) \cdot$ M. Lebrun

Cirad \& UM2, LSTM, UMR 113, TA A-82/J

Campus International de Baillarguet,

34398 Montpellier Cedex 5, France

e-mail:marc.ducousso@cirad.fr

M. Lebrun

e-mail: lebrun@univ-montp2.fr

S. Gianinazzi

UMR 1088 INRA/Université de Bourgogne et FRE/CNRS 2625

Plante-Microbe-Environnement, INRA-CMSE,

BP 86510, 21065 Dijon Cedex, France

e-mail: silvio.gianinazzi@dijon.inra.fr

C. Leyval

Laboratoire des Interactions Microorganismes-Minéraux-Matière

Organique dans les Sols, Faculté des Sciences,

UMR 7137 CNRS-Nancy University,

BP 70239, 54506 Vandoeuvre-lès-Nancy Cedex, France

e-mail: corinne.leyval@limos.uhp-nancy.fr tions (53) and posters (61) were organised into three sessions devoted to: mycorrhizal symbiosis and performance of the eco- and agro systems, mycorrhizal symbiosis and rehabilitation of soils, and biotechnology of mycorrhizal inoculations and their applications. In the opening lecture, Thierry Gauquelin addressed the question What are Mediterranean ecosystems and environments? He presented the complexity, limits, and characteristics of the Mediterranean region, giving the framework of this congress.

In Mediterranean countries, performances of eco- and agro systems largely depend on plant-associated microorganisms because of their role in plant adaptation to environmental stresses such as drought, high disturbance, poor soils, etc. The first session on Mycorrhizal symbiosis and performance of the eco- and agro systems was opened by a lecture from Jean Garbaye highlighting long-term consequences of human activities on diversity and functioning of ectomycorrhizal species. This was followed by a presentation illustrating the complexity of Acacia taxonomy with regard to the diversity of their microbial symbioses (nitrogen-fixing nodules, arbuscular mycorrhiza, ectomycorrhiza) and communications showing how the mycorrhizal symbiosis may influence structural and functional diversity of soil microflora, particularly mycorrhizospheric bacterial populations. A full understanding of the impact of complex interactions between soil microorganisms on ecosystem organization is still a long way off, but research is actively contributing. Another 16 talks about diverse ecosystems in Mediterranean and Sahelian regions focused on the possible role of mycorrhizae in positive effects of shrub on high-altitude tree species establishment, the importance of ectomycorrhizal fungi in plant management and adaptation to particular soil conditions, new ways of land management aimed at enhancing edible Boletus and Terfez production, arbuscular mycorrhizal inoculation of crops, mycorrhizal fungal population density 
and diversity, and mycorrhiza-based conservation strategies. A new database dedicated to ectomycorrhizal communities ("Ectomycorrhizal Community Database", eMyCo) was described in the final talk. Similar topics were considered in 29 posters.

Mediterranean soils are suffering from diverse degradations, due to dryness, overexploitation, pollution with heavy metals and other pollutants, high salt concentrations and biotic factors. In her introductory lecture of the session on Mycorrhizal symbiosis and rehabilitation of soils, Corinne Leyval presented recent results on the beneficial effects of arbuscular mycorrhiza for plants in metallic and organic polluted soils, which confirmed that the contribution of arbuscular mycorrhizal fungi to plant tolerance to pollutants is affected by many parameters, including pollutant type and bioavailability, the plant, soil conditions, and the associated fungi. In the 20 oral presentations which followed, topics covered different abiotic stresses including salt stress, heavy metals, other pollutants and multi contaminations, water stress, soil restoration, biotic stress (pathogens, invasive plants), and effects of agricultural practices (conventional or organic) on arbuscular mycorrhizal fungi. In the 22 posters, the same topics were also considered. These presentations highlighted the efforts to analyse, select, and identify mycorrhizal fungi adapted to adverse conditions, as well as host-plant species or cultivars, potentially usable for stress tolerance, revegetation, and in situ soil remediation. Reported results, from laboratory, greenhouse, and field experiments, were promising and showed that mycorrhizal fungi, often associated with other soil organisms, could contribute to soil rehabilitation and are key components of soil restoration. Many different mycorrhizal fungi have been isolated from different Mediterranean soils which creates the need for databases and conservation strategies to maintain these valuable resources and relevant information about the areas.
In many Mediterranean regions, the mycorrhizal potential of soils is decreasing, and there is a need to reintroduce symbiotic fungi to improve productivity and sustainability of agro ecosystems. After the introductory lecture by Silvio Gianinazzi in which he reviewed the present situation on the topic of the session Biotechnology of mycorrhizal inoculations and their applications, oral presentations (10) underlined the potential of controlled mycorrhization in crop production and pointed to the need for an industrial development of inoculum production. Although industries producing inocula are developing all over the world, this is largely insufficient in Mediterranean countries and needs to be implemented. Also, the quality of inoculum production is a determinant for the promotion of this new biotechnology, and there is a need to define widely accepted standards for quality control. A very innovative aspect for mycorrhizal research in several presentations was the potential of mycorrhization to improve food and grain quality, with examples taken from plants like lettuce, melon, almond, and Medicago. This was also illustrated for vitroplants where mycorrhization improves not only plant growth but also the quality of the future crop, notably resistance to pathogenic agents. A presentation on Terfez production associated with the development of mycorrhizal Argan plantations showed how mycorrhizal biotechnology opens possibilities to valorise poor ecosystems by developing high biological input plant production systems based on added value crops. Similar topics were covered by 17 posters in the session.

In addition to the overall high quality of both oral and poster presentations, the quality and the richness of the debates which they stimulated contributed to the success of the meeting. Thanks and felicitations to the organising committee for this interesting and productive conference. 